\title{
Takotsubo Cardiomyopathy: Role of Cardiac MRI
}

\author{
Selvakumar Subbaraman ${ }^{1 *}$, Seena Cheppala Rajan ${ }^{1}$, Saveetha Veeraiyan $^{1}$, Paarthipan Natarajan $^{1}$ \\ 1. Department of Radiodiagnosis, Saveetha Medical College and Hospital, Chennai, India \\ * Correspondence: Selvakumar Subbaraman, AA102, New no.2, 1st Street, 3rd Main Road, Annanagar, Chennai 600040, Tamilnadu, \\ India \\ (邓drselva73@gmail.com)
}

Radiology Case. 2021 Jun; 15(6):26-32 :: $\quad$ DOI: $10.3941 /$ jrcr.v15i6.4138

\begin{abstract}
We present a case of Takotsubo Cardiomyopathy (TC) which is a non ischemic cardiomyopathy. It is stress related and also known as broken heart syndrome. The patient presented to our emergency department with symptoms of chest pain and breathlessness. The patient was diagnosed as acute coronary syndrome and various tests including ECG, Screening ECHO, Coronary CT and Cardiac Magnetic Resonance (CMR) were done before arriving at the diagnosis of TC. Currently CMR is the modality of choice as it detects the wall motion abnormalities (WMA), presence of wall edema and late gadolinium enhancement (LGE) characteristics can be well appreciated. No intervention was done and the case was managed medically.
\end{abstract}

\section{CASE REPORT}

\section{CASE REPORT}

A 67 year old lady was brought to our ER with symptoms of chest pain and breathlessness. The husband told that the symptoms started 30 minutes after hearing the news of her sister's demise.

This prompted our physician to think of TC and hence tests were done to confirm the diagnosis. The cardiac enzymes were mildly elevated but inconclusive. ECG showed mild to moderate ST elevation and left bundle branch block.

Echocardiography showed akinesia of the apical and midventricular segment while the basal segments were hypercontractile. The apex was dilated (apical ballooning). Mild to moderate degree of left ventricular dysfunction was noted. Coronary CT was also done to assess the coronary arteries. The coronary CT did not show any significant occlusion of the coronary arteries. The CMR performed showed mild apical ballooning and wall motion abnormality involving the apical and mid ventricular segments. Patchy wall edema was noted in the mid and apical segments on fat suppressed sequence. LGE was not seen.

The patient was managed medically with beta blockers, Angiotensin Converting Enzyme Inhibitors and short-term anticoagulants. She was stabilised and discharged in good health after 4 days of admission. She was instructed to continue the medications and to review after 3 months.

\section{DISCUSSION}

\section{Etiology \& Demographics:}

Takotsubo cardiomyopathy is a reversible cardiomyopathy. It is often precipitated by a stressful event. The clinical features are similar to acute myocardial infarction. Usually, women in the postmenopausal age group are affected. Takotsubo is a Japanese word meaning octopus trap. This reversible cardiomyopathy is characterized by hypokinesia or akinesia in the mid and apical segments of the left ventricular (LV) wall with typical sparing of the basal segments and with 
absence of obstructive coronary lesions. The prognosis is excellent, and the LV function recovers completely. All these features are well seen on CMR [1]. Takotsubo is a pot used by the Japanese to catch octopus (Figure 1). While performing left ventriculography, Dote et al [2] first described Takotsubo cardiomyopathy, when he saw that the left ventricle actually resembled the Japanese pot to trap the octopus.

The importance of knowing about this disease entity and identifying the disease is very important because of its clinical similarity with other acute coronary syndromes (ACS) that require acute treatment and have a worse prognosis. TC is completely reversible with a good prognosis.

\section{Pathophysiology:}

The four theories explaining [3] the cause of the disease are:

1. Spontaneous thrombolysis of the thrombus formed in the coronary arteries.

2. Multiple coronary vasospasms.

3. Microcirculatory dysfunction.

4. Catecholamine stunning.

TC has been reported in up to $2.2 \%$ of patients presenting with ACS to the hospital, and as more physicians are becoming aware of this disease, this percentage will increase soon with an increase in the detection rate. Among the different diagnostic tools available, the role of CMR has significantly increased. CMR allows not only the morphologic and dynamic assessment of the heart but also shows the myocardial inflammation / scaring with the use of Gadolinium.

\section{Clinical \& Imaging findings:}

\section{MRI Imaging protocol}

Cardiac MR imaging [4] in TC and other ACS needs to assess the presence or absence of structural abnormalities, to evaluate the presence of myocardial edema and scarring. MR scanners should be $1.5 \mathrm{~T}$ or higher with coils for cardiac imaging.

For structural abnormalities, T1 gated sequences in short and long axis and a four-chamber plane, as well as free precession breath-hold cines in short and long axis and outflow tract are useful. For myocardial edema, T2 weighted images with triple inversion recovery (IR) in the short and long axis, as well as a four-chamber acquisition is recommended. Lastly, to assess for the presence or absence of scarring, ten minutes after Gadolinium injection, short and long axis acquisitions identical to the ones done in cine mode are performed using an IR gradient echo sequence. The descriptions of the sequences we use clinically are given below in Table 1.

The modified Mayo Clinic diagnostic criteria [5] for Takotsubo cardiomyopathy are:

1. Presence of transient hypokinesia, akinesia, or dyskinesia in the LV mid and apical segments with wall motion abnormalities that extend beyond a single epicardial vascular distribution and frequently, but not always, of a stressful trigger.

2. Absence of obstructive coronary disease or angiographic evidence of acute plaque rupture.
3. New ECG changes with ST-segment elevation or Twave inversion and usually elevation of cardiac markers

4. Absence of pheochromocytoma and myocarditis.

\section{Edema}

Edema is the result of an inflammatory process and has been proved by correlating with endomyocardial biopsies. In $\mathrm{TC}$, the area of edema corresponds to the area of WMA, however it is difficult to differentiate it from edema due to other causes like myocarditis. Late gadolinium enhancement (LGE) is usually relied upon to differentiate, although myocarditis without LGE can also happen. The laboratory findings, the age of the patient and other imaging findings may help in the differential. Another indicator of the role inflammation plays in TC, is the slight association between wall edema and pericardial effusion [6]. Typically, T2weighted sequences in TC patients shows the presence of circumferential, transmural oedema of the apical to mid-cavity myocardium matching with the regional wall motion abnormalities. Myocardial oedema is a transient dynamic phenomenon, normally progressively resolving between 3 to 6 months.

Myocardial edema (Figure $2 \& 3$ ) on CMR is a constant feature in TC, reflecting acute inflammation.

Left Ventricular function and Wall Motion Abnormalities:

The presence of a reversible systolic impairment of LV function affecting mainly the LV apex is one of the hallmark features of TC (Figure 4). The regional wall motion abnormality extends beyond a single epicardial vascular distribution. The typical form presents with contraction abnormalities in the ventricular wall, equally affecting the anterior, inferior and lateral walls, which extend beyond a single epicardial vascular territory. Another finding suggestive of TC is the hyperkinesia of basal segments contributing to the characteristic morphology.

A mid-cavity to apical ballooning with sparing of the LV basal segments occurs typically [7]. However, other contraction patterns that are observed during the acute phase of TC including mid-ventricular, basal and focal forms may be seen in up to $18 \%$ of the cases [8] complete recovery in $96 \%$ of patients occurs within 7-37 days. It has been observed that typical and mid-ventricular TC forms have more severe heart failure symptoms.

\section{Late Gadolinium Enhancement (LGE):}

To assess for the presence/absence of myocardial scarring. The edema of the myocardium usually resolves without any myocardial scarring leading to full functional recovery. The main use of LGE is to identify the presence and assess the amount of myocardial damage. Early CMR studies have shown that absence of LGE is a must for the diagnosis of TC (Figure 5). Lack of LGE differentiates it from MI and other cardiomyopathies [9].

However, some reports do say that LGE can be present in TC which may be due to delayed washout of the gadolinium due to increased interstitial water content. 


\section{Treatment \& Prognosis:}

TC is a condition which is medically managed. Supportive care is needed till the LV function is restored. Beta blockers and Angiotensin Converting Enzyme inhibitors are commonly used. These drugs promote the recovery of the muscle. To prevent clot formation short term use of anticoagulants is also advocated. The hospital stay of our patient was for 4 days (mean is between $3-7$ days). Antianxiety or beta blockers are prescribed on long term basis to alleviate stress.

\section{Complications:}

The possible complications are: left heart failure with or without pulmonary edema, acute pericarditis, mitral valve regurgitation, ventricular arrhythmias, intramural thrombus, stroke, LV free wall rupture and even death [10]. Most of these complications are diagnosed with CMR.

Close follow up with a cardiologist is advised and complete recovery occurs within 3-6 months. Follow up imaging can be done with either ECHO or CMR.

\section{Differential Diagnosis:}

The findings are typical for TC and CMR will easily differentiate it from other condition like myocarditis, cardiomyopathy and ischemia. Ischemia usually involves the subendocardial or transmural enhancement depending on the amount of muscle layer involved. Non ischemic causes are differentiated based on the distribution of the delayed enhancement. Myocarditis usually involves mid myocardium.

\section{TEACHING POINT}

Takotsubo Cardiomyopathy is characterized by history of recent stress, absence of significant coronary artery stenoses, presence of wall edema, apical ballooning with wall motion abnormality (hypokinesia or akinesia in the mid and apical segments of the left ventricular (LV) wall with typical sparing of the basal segments and lack of LGE.

\section{REFERENCES}

1. Andres Alejandro Kohan, Ezequiel Levy Yeyati, Luciano De Stefano et al, Usefulness of MRI in Takotsubo cardiomyopathy: a review of the literature, Cardiovascular Diagnosis and Therapy, 2014 Apr; 4(2): 138-146. PMID:24834411

2. Dote K, Sato H, Tateishi H, et al. Myocardial stunning due to simultaneous multivessel coronary spasm: a review of 5 cases, J cardiol 1991:21:203-14, PMID: 1841907

3. Konstantinos Bratis, Cardiac Magnetic Resonance in Takotsubo Syndrome, Eur Cardiol. 2017 Aug; 12(1): 58-62. PMID:30416553

4. Gabriel C Fernandez at al, Takotsubo cardiomyopathy:Assessment with cardiac MRI, AJR.2010;195:W139-145.10.2214/AJR09.3369, PMID: 20651173

5. Galiuto L, De Caterina AR, PorfidiaA et al. Reversible coronary microvascular dysfunction: a common pathogenetic mechanism in Apical Ballooning or Tako-Tsubo Syndrome. Eur Heart J. 2010;31:1319-27. PMID:20215125.

6. Kurisu S, Sato H, Kawagoe T et al. Takotsubo-like left ventricular with ST-segment elevation: a novel cardiac syndrome mimicking acute myocardial infarction. Am Heart J. 2002;143:448-55. PMID:11868050

7. Arias AM, Oberti PF, Pizarro R, et al. Dobutamineprecipitated Takotsubo cardiomyopathy mimicking acute myocardial infarction: a multimodality image approach, Circulation 2011;124:e312-5. PMID 21931096.

8. Abraham J, Mudd JO, Kapur NK et al. Stress cardiomyopathy after intravenous administration of catecholamines and beta-receptor agonists. J Am CollCardiol. 2009;53:1320-5. Doi10.1016/j.jacc.2009.02.020., PMID: 19358948

9. Bybee KA, Kara T, Prasad A, et al. Systematic review: transient left ventricular apical ballooning: a syndrome that mimics ST-segment elevation myocardial infarction. Ann Intern Med 2004;141:858-65,PMID:15583228

10. Pernicova I, Garg S, Bourantas CV, et al. Takotsubo cardiomyopathy: a review of the literature. Angiology 2010;61:166-73, PMID:19625263 


\section{FIGURES}
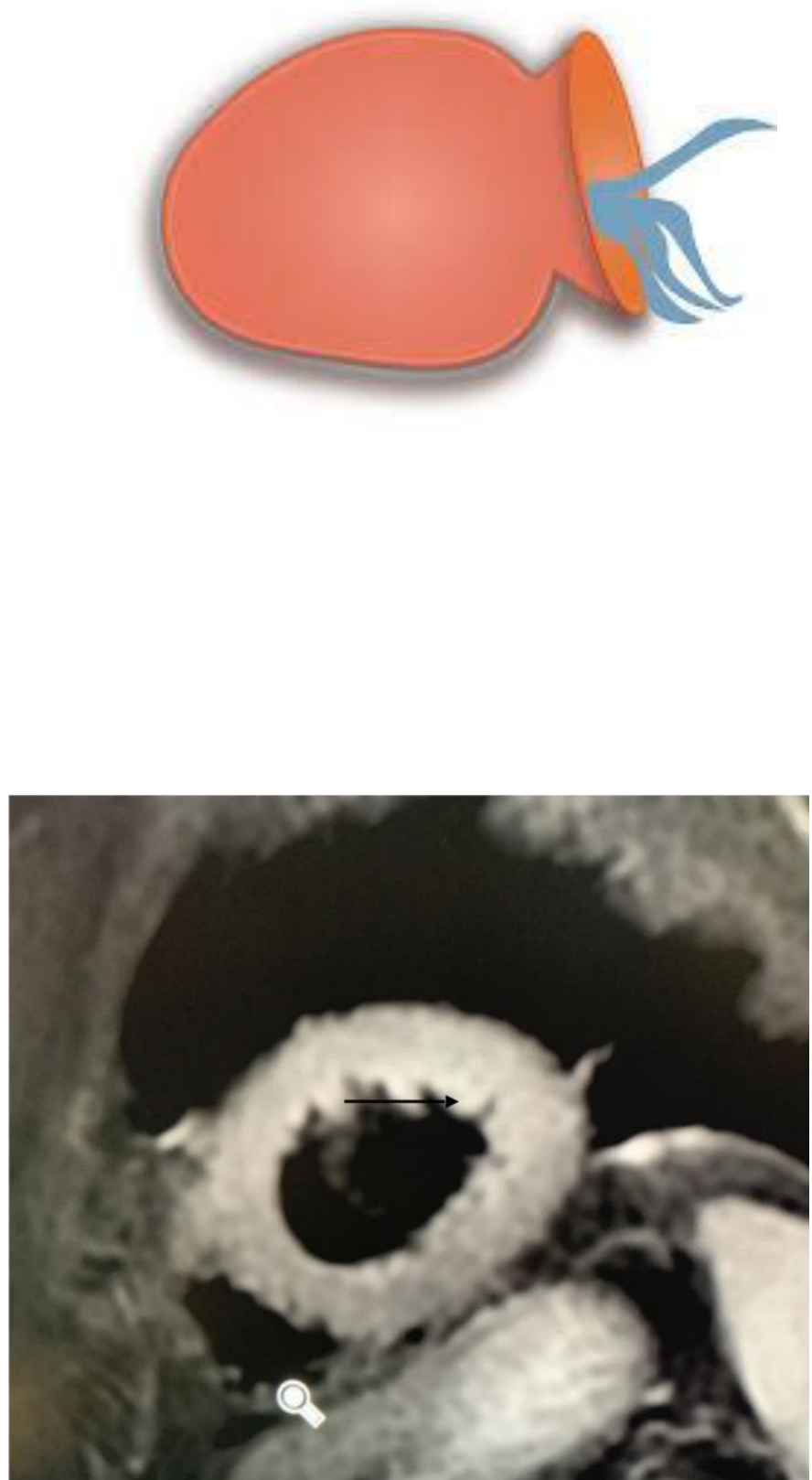

Figure 2: 67-year-old woman with Takotsubo cardiomyopathy.

Findings: Cardiac MR done on GE 3T MRI. Sagittal short axis STIR images of the left ventricle at the apical region showing patchy wall edema (black arrow).

Technique: TR 1600, TE 54, TA 107, 512 X 512 matrix, no contrast.
Figure 1 (left): Takotsubo (octopus trap) pot with a narrow neck used in Japan to catch octopus.

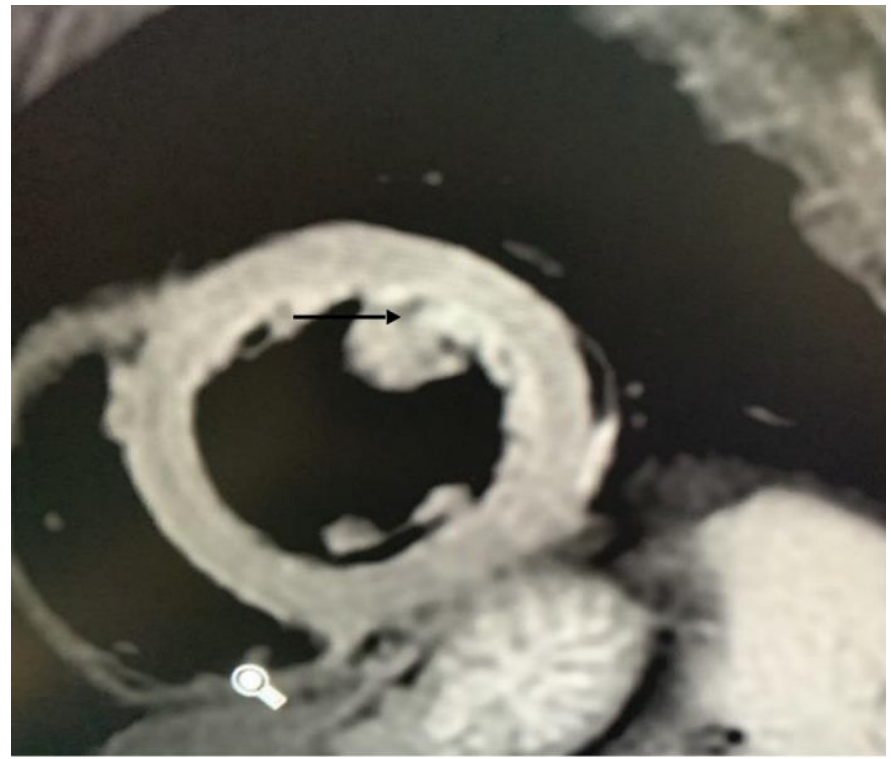

Figure 3: 67-year-old woman with Takotsubo cardiomyopathy.

Findings: Cardiac MR done on GE 3T MRI. Sagittal short axis STIR images of the left ventricle at the mid region showing patchy wall edema (black arrow).

Technique: TR 1600, TE 54, TA 107, 512 X 512 matrix, no contrast 


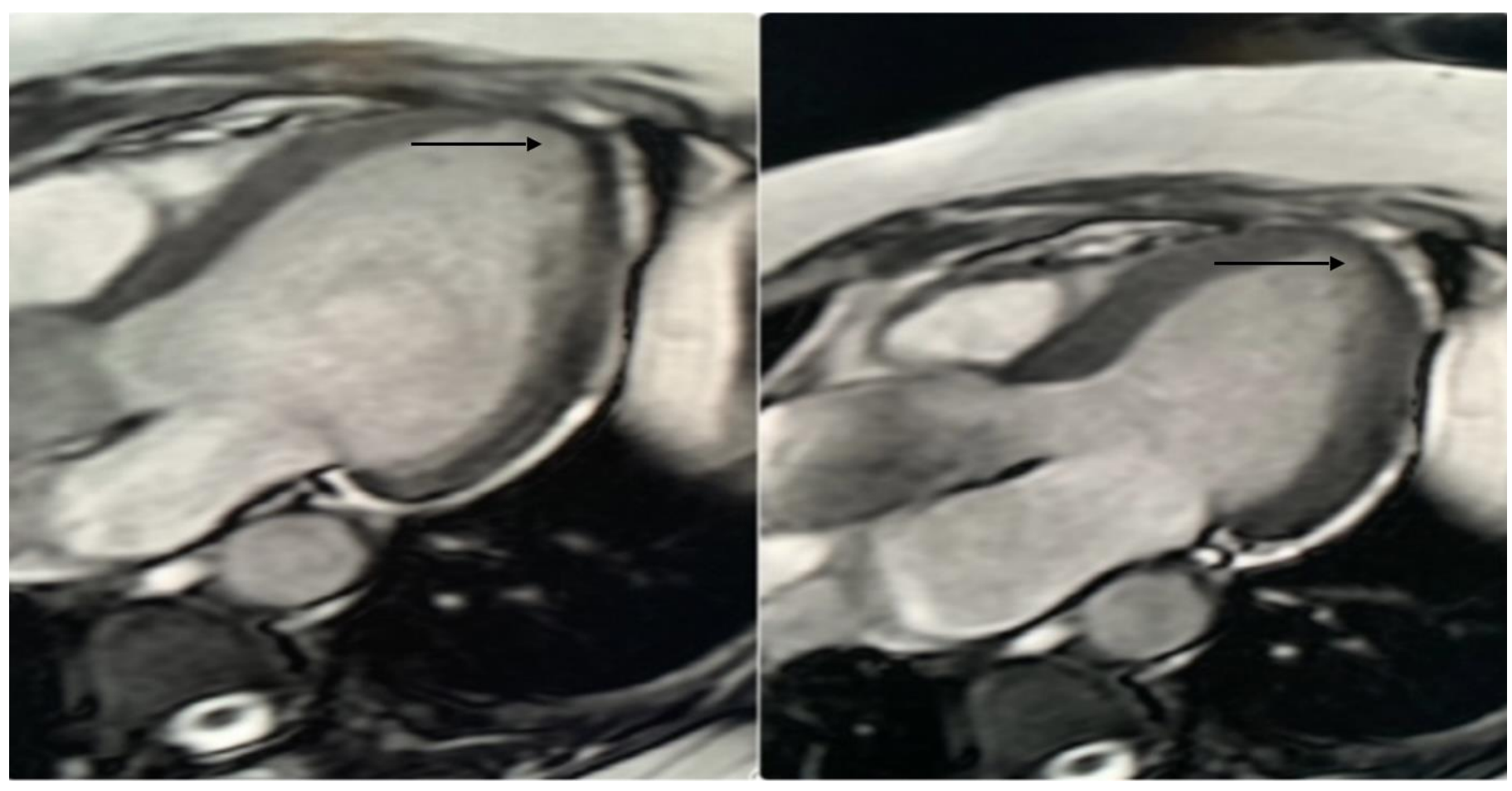

Figure 4: 67-year-old woman with Takotsubo cardiomyopathy.

Findings: Cardiac MR done on GE 3T MRI. Fig 4a, Axial 3 chamber white blood image at diastole and Fig 4b, Axial 3 chamber white blood image at systole shows ballooning of the left ventricle apex (black arrow) which is characteristic of TC.

Technique: TR 3.45, TE 1.40, TA 55, 512 x 512 matrix , no contrast.

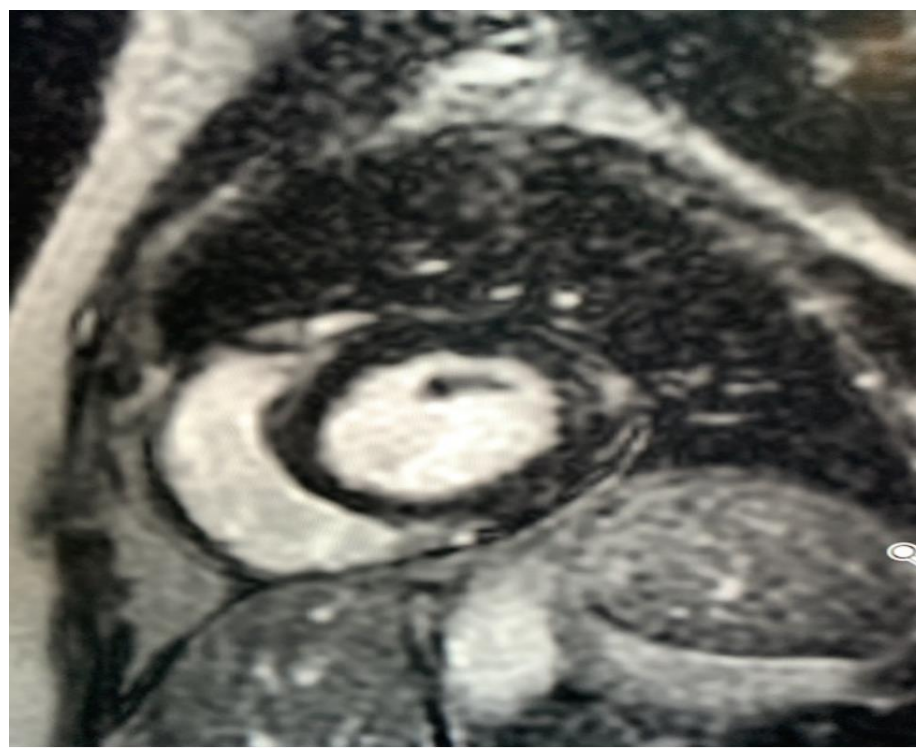

Figure 5 (left): 67-year-old woman with Takotsubo cardiomyopathy.

Findings: Post contrast Cardiac MR done on GE 3T MRI. Post contrast, short axis sagittal images of the left ventricle at the mid cavity showing no LGE.

Technique: TR 3.59, TE 1.45, TA 55, 512 x 512 matrix. Post contrast study done 10 mins after intravenous administration of gadolinium. 


\begin{tabular}{|c|c|c|c|}
\hline Protocol & Sequence & Planes & Usefulness and Current Utilization \\
\hline Scout & $\begin{array}{l}\text { Balanced Steady State Free } \\
\text { Precession (bSSFP) } \\
\text { Non-ECG-gated }\end{array}$ & $\begin{array}{l}\text { Transaxial, coronal and sagittal } \\
\text { covering the entire thorax }\end{array}$ & $\begin{array}{l}\text { Standard for all CMR studies } \\
\text { Easily identify pleural and pericardial } \\
\text { effusions }\end{array}$ \\
\hline Edema & $\begin{array}{l}\text { Black blood T2-weighted (fast } \\
\text { spin echo) triple-inversion } \\
\text { recovery (IR) }\end{array}$ & $\begin{array}{l}\text { Short-axis plane covering the } \\
\text { LV } \\
\text { Slice thickness }=8 \mathrm{~mm}\end{array}$ & $\begin{array}{l}\text { Recommended for differential } \\
\text { distinction from myocarditis or acute } \\
\text { MI. Usual finding is increase SI in } \\
\text { mid-apical segments }\end{array}$ \\
\hline T1-Mapping & $\begin{array}{l}\text { Modified Look-Locker (MOLLI), } \\
\text { Shortened Modified Look-Locker } \\
\text { Inversion Recovery (ShMOLLI), } \\
\text { saturation recovery single shot } \\
\text { acquisition (SASHA), others }\end{array}$ & $\begin{array}{l}\text { Short-axis plane covering the } \\
\text { LV with specific TI }=100- \\
5000 \mathrm{~ms} \text {, collected using bSSFP } \\
\text { readouts } \\
\text { Slice thickness }=8 \mathrm{~mm}\end{array}$ & $\begin{array}{l}\text { Research tool that may serve as a } \\
\text { complementary technique to T2- } \\
\text { weighted imaging. Quantitative means } \\
\text { to detect myocardial edema without } \\
\text { the need for reference ROIs }\end{array}$ \\
\hline T2-Mapping & $\begin{array}{l}\text { T2-prepared single-shot SSFP } \\
\text { sequence, Multiecho FSE } \\
\text { (MEFSE), others }\end{array}$ & Matching short-axis T1 & $\begin{array}{l}\text { Application under research evaluation. } \\
\text { T2 values more closely correlate with } \\
\text { free water tissue content over T1- } \\
\text { based techniques in suspected } \\
\text { myocardial inflammation. It may offer } \\
\text { a more stable and truly quantitative } \\
\text { alternative for edema detection in } \\
\text { cases when conventional T2-weighted } \\
\text { imaging fails, especially in thin and } \\
\text { rapidly moving walls }\end{array}$ \\
\hline $\begin{array}{l}\text { Morphology } \\
\text { and Function }\end{array}$ & $\begin{array}{l}\text { Balanced steady state Free } \\
\text { precession (bSSFP) }\end{array}$ & $\begin{array}{l}\text { Short-axis plane covering entire } \\
\text { LV } \\
\text { Long-axis }-3 \text { slices each plane } \\
(2 \mathrm{CH}, 4 \mathrm{CH} \text { and LVOT) } \\
\text { Slice thickness }=6-8 \mathrm{~mm} \\
\text { Interslice gap }=2-4 \mathrm{~mm}\end{array}$ & $\begin{array}{l}\text { Mandatory for all CMR studies } \\
\text { investigating TC. It will give } \\
\text { information on the hallmark of the } \\
\text { disease, regional abnormal } \\
\text { contractility not related to coronary } \\
\text { territory }\end{array}$ \\
\hline LGE & $\begin{array}{l}10 \text { min after Gd bolus } \\
\text { 2D segmented IR gradient echo } \\
\text { with or without Phase-Sensitive } \\
\text { IR (PSIR) } \\
\text { Single-shot or 3D versions of } \\
\text { LGE can also be used. }\end{array}$ & $\begin{array}{l}\text { Short-axis plane covering LV } \\
\text { (especially mid-apical segments) } \\
\text { Long-axis }-1 \text { or more slice each } \\
\text { plane }(2 \mathrm{CH}, 4 \mathrm{CH} \text { and LVOT) } \\
\text { Slice thickness }=8 \mathrm{~mm} \\
\text { Interslice gap }=2\end{array}$ & $\begin{array}{l}\text { The usual finding in TC is absence of } \\
\text { significant myocardial LGE by visual } \\
\text { analysis. Quantitative analysis using } \\
\text { software with a variety of thresholds } \\
\text { techniques can detect small amounts } \\
\text { of patchy LGE. }\end{array}$ \\
\hline
\end{tabular}

Table 1: List of commonly used Cardiac MR Sequences.

\begin{tabular}{|l|l|}
\hline Etiology & Stress related, non-ischemic Cardiomyopathy \\
\hline Prevalence & 1 to $2 \%$ \\
\hline Clinical Presentation & chest pain, breathlessness (like Acute Coronary Syndrome) \\
\hline Gender & More common in women \\
\hline Age Predilection & Post-menopausal, mean age 66 \\
\hline Risk factors & Domestic abuse, death of relatives, natural calamities, accident or major trauma, arguments. \\
\hline Treatment & Beta blockers, ACE Inhibitors, anticoagulants, alleviation of stress \\
\hline Prognosis & Excellent. Completely reversible in 3-6 months. \\
\hline Imaging findings & $\begin{array}{l}\text { Wall motion abnormality with apical ballooning (ECHO and CMR), Wall Edema (CMR), No LGE } \\
\text { (CMR) }\end{array}$ \\
\hline
\end{tabular}

Table 2: Summary table of Takotsubo Cardiomyopathy. 


\begin{tabular}{|l|l|l|l|l|}
\hline No & Condition & LGE pattern in CMR & Wall Edema & WMA \\
\hline $\mathbf{1 .}$ & $\begin{array}{l}\text { Takotsubo } \\
\text { Cardiomyopathy }\end{array}$ & No LGE & present & Apical ballooning and non-coronary distribution. \\
\hline $\mathbf{2}$ & Ischemic & $\begin{array}{l}\text { Subendocardial or } \\
\text { Transmural }\end{array}$ & Absent & Absent \\
\hline $\mathbf{3}$ & $\begin{array}{l}\text { Myocarditis, } \\
\text { Hypertrophic } \\
\text { cardiomyopathy }\end{array}$ & Mid wall & Absent & regional \\
\hline $\mathbf{4}$ & $\begin{array}{l}\text { Sarcoidosis, } \\
\text { Myocarditis }\end{array}$ & Subepicardial & In active disease & Focal thinning with non-coronary distribution \\
\hline
\end{tabular}

Table 3: Differential diagnosis table for Takotsubo Cardiomyopathy.

\section{ABBREVIATIONS}

ACS = Acute Coronary Syndrome

$\mathrm{CMR}=$ Cardiac Magnetic Resonance

$\mathrm{IR}=$ Inversion Recovery

LGE = Late Gadolinium Enhancement

$\mathrm{LV}=$ Left Ventricle

$\mathrm{TC}=$ Takotsubo Cardiomyopathy

WMA = Wall Motion Abnormality

\section{KEYWORDS}

Takotsubo; Broken heart syndrome; chest pain; cardiac MRI; stress cardiomyopathy

\section{Online access}

This publication is online available at:

www.radiologycases.com/index.php/radiologycases/article/view/4138

\section{Peer discussion}

Discuss this manuscript in our protected discussion forum at www.radiolopolis.com/forums/JRCR

\section{Interactivity}

This publication is available as an interactive article with scroll, window/level, magnify and more features.

Available online at www.RadiologyCases.com

\section{Published by EduRad}

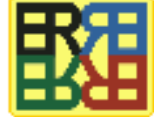

www.EduRad.org 